\title{
Click Here For Reality: Enhancing Student Engagement
}

\author{
Susan P. Eisner, (E-mail: seisner@ramapo.edu), Ramapo College of New Jersey
}

\begin{abstract}
This paper presents three initiatives designed to advance undergraduate learning outcomes by enhancing student engagement through active, reality-based learning. The Team Challenge, Management Consultant Simulation, and Bookstore Adventure are described.
\end{abstract}

\section{INTRODUCTION}

$T$

his paper continues a stream of research conducted by its author in recent years to identify, implement, and assess contemporary pedagogy that would facilitate learning for today's primarily Generation $\mathrm{Y}^{1}$ college students. That research has consistently found the effectiveness of modalities designed to actively engage students in their learning, and to incorporate experiences and vehicles students frequent and value in the totality of their lives. Such modalities, then, have three core attributes: the learning is active, experiential, and empathetic ${ }^{2}$. These findings and resulting initiatives are particularly relevant and timely at the School of Business at Ramapo College, which is preparing to enter candidacy for AACSB accreditation.

AACSB International accreditation standards encourage faculty to actively involve students in the learning process, and to facilitate collaboration and cooperation among participants. The standards specify learning experiences that include group and individual dynamics, communication, reflective thinking, ethical knowledge and reasoning, and multicultural and diversity understanding ${ }^{3}$. Similarly, the Seven Principles in Action identified by the American Association for Higher Education as central to effective learning advance the importance of active learning. The importance of prompt feedback, cooperation among students, time on task, high expectations, respect for diverse talents and different ways of learning, and effective student-faculty contact is reported ${ }^{4}$.

This paper presents three resulting initiatives designed to advance undergraduate learning outcomes by enhancing student engagement through active, reality-based learning at Ramapo College of New Jersey, a mid-size four-year public college located about 35 minutes from New York City. In recent years, Ramapo College has been ranked \#1 among public comprehensive colleges in the North by U.S. News and World Reports ${ }^{5}$. The Team Challenge, Management Consultant Simulation, and Bookstore Adventure are described below so that they may contribute to pedagogical literature, and be available to colleagues who may also be wrestling with how to optimize learning and so may find them useful to consider. The initiatives have been used in General Education as well as Business School classes, resonated with students majoring in all disciplines, and can be adapted for use throughout the curriculum.

\section{INITIATIVE 1: THE TEAM CHALLENGE}

This initiative was conceived as a pedagogical tool to counter dynamics that had presented themselves while teaching prior sections of a 300-level Business Communication course, which fulfills an elective requirement in the Management program. The course develops the central workplace skill of being able to achieve common understanding - to exchange messages in ways that will be understood and accepted. Students use strategic approaches to achieve interpersonal, written, and oral competence and confidence, and direct these tools toward their interests and progress. Situations covered include informational and persuasive messages, good and bad news, audience, style, team collaboration, technology/graphics, gender/intercultural communication, career building, interviewing, listening, meetings, and ethics. The successful student masters core course concepts through the strategic interpersonal use of 
written, oral, and electronic communication to achieve business goals. The syllabus specifies course objectives as enabling its students to understand that business communication occurs in many settings for many purposes, develop the judgment and analytic ability essential to successful communication, apply communication techniques to solve business problems and create opportunities, and build practical skills needed to communicate effectively both at work and academically ${ }^{6}$.

Colleagues who have taught Business Communication as a business school course often speak of the need for contemporary pedagogy to facilitate achievement of those objectives. The experience of this author concurs. In the absence of active student involvement, the course too readily defaults to an exercise in disinterested memorization rather than to the robust experience of building and applying practical skills that is its goal. The former possibility is all the more likely since most students have been taught technical writing and speaking from their earliest schooling, and so are inclined to perceive business communication as common sense rather than core competence unless they experience the intricate and strategic nature of its central skill sets firsthand.

Frankly, that conundrum was wrestled with for several semesters before it was pinpointed. Successful experience with active learning modalities in other courses ${ }^{7}$ suggested that activities designed to directly engage students in this course might also be effective. Two basic objectives for such pedagogy were identified: 1) to ensure that required readings and cases were completed and processed prior to the session where they would be discussed, and 2) to stimulate generation of creative alternatives and critical evaluation of them through shared dialog with peers. Seeking a conceptual base students could readily relate to, Reality TV programs like Survivor, The Apprentice, and American Idol that were attracting widespread student viewing came to mind. What did these programs have in common? They were anchored in real-world experiences with which viewers identify, and they involved competition. With this in mind, the Team Challenge described in Figure 1 was designed and assigned the second time the class met. Teams were assigned; each team reflected the students' demographic and psychographic diversity.

\section{Figure 1: Business Communication Team Challenge}

\section{TEAM CHALLENGE}

This exercise was created for this course to help its students understand through firsthand experience the dynamic nature of business communication, and to develop competence and confidence in its strategic use to leverage opportunities and mediate challenges they will encounter as practitioners. You will work in competing teams learning from assigned cases. Teams will be assigned and reflect the myriad of your talents, interests, and attributes.

The Assignment: As a team, analyze the end-case (Communication Challenge at Hawaii Hotel) for Chapter 2 in your textbook, after reading the chapter. Cover the following points in a $3+-$ page team memo report, and present them to the class in an informal $\underline{5}$-minute oral report at next week's class. Follow this format:

- $\quad$ List $\underline{3}$ main or interesting points about the case, briefly defining any new terms.

- List $\underline{3}$ terms from the chapter illustrated by the case, and define each term in your own words.

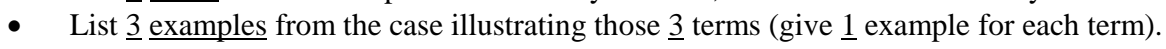

- Give 1 critical thinking question practitioners might raise that was stimulated by your analysis of the case.

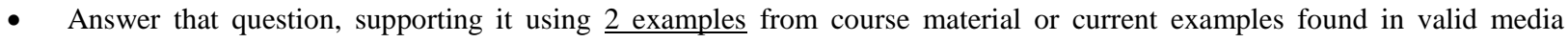
sources.

- Explain what communication strategies you would use if you were the manager in this case and why, using your learning in this course to support your recommendation.

Assessment: After the oral reports, the class will vote on which team presented the best work. Teams may not vote for themselves, and individual votes will be known only to the instructor. The team voted as best will receive extra credit toward its members' course participation grades; in the case of a tie, members of both teams will receive extra credit. The written memo reports will be collected and assessed by the instructor. The team(s) that wrote the best memo report will receive extra credit. All students will be graded for participation, which includes anonymous peer assessment. Attendance is expected; absence and/or lack of preparation/contribution will affect the class adversely and significantly lower one's course participation grade. A member of a winning team who is absent will not share the extra credit earned by the team, unless s/he contributed fully to the team's work and the absence is medically documented. 
In prior semesters, required textbook reading and end-case analysis was to be done by each student as preparation for the class. Although most did the reading, knowing they would be asked to reflect upon it in class, the level of interest and learning were minimal for most. That pattern had triggered creation of the Team Challenge. But would it backfire? Would students working in teams reinforce each other's antipathy, and spiral into shared resistance to learning? Would that possibility be magnified since most of the students did not know each other?

The Team Challenge delivered the opposite result; desired outcomes were achieved. On their own time, between class meetings, the students had become energetic learning communities with tangible outcomes to deliver and meaningful measurements to receive. Analysis was reasoned, and discussion was animated. What had been assigned as informal oral presentations were, by team initiative, delivered formally and thoughtfully - complete with audiovisual aids and interactive components. After the presentations were completed, all teams were affirmed for their effort and contribution to course learning. With their presentations fresh on their minds, the class was given immediate and constructive feedback regarding techniques that would help them deliver future presentations with even more impact. No student was absent, and peer assessment revealed no student having shirked responsibility to his/her team.

Debriefing the class immediately after completion of the assignment revealed that several factors contributed to its strong reception: the case had been translated into a scenario in which students had a role to play, that role related to their learning in the class, teamwork provided a deadline and forum for preparatory reading, diversity fostered creativity, no one wanted to be the one to let the teammates down, quality work would be rewarded, and teams were competing for that reward. Students were then asked if they would like to do another Team Challenge for material to be completed for their next class. The decision was unanimous. The class chose to continue the Team Challenge week after week. To support the ancillary learning opportunity that presented, guidelines for building and performing effective group work contained in Figure 2 were constructed and distributed, as was the peer assessment form in Figure 3. During each session, at least one technique for averting and overcoming conflicts that might arise between members of a team was infused.

As the semester progressed and foundational course concepts were assimilated, it was postulated that students had become accustomed and able to process required readings and would continue to do so outside the framework of a Team Challenge. Further, it was possible that some of the initial interest the Team Challenge had sparked might erode if the only variables were the chapter and case to be addressed. As a result, as halfway through the course subject matter turned to oral presentation, the Team Challenge was retooled. Students were informed that they were now ready to cover the readings and cases on their own prior to class, and that if they chose to continue the Team Challenge it would focus on new skill sets we would be covering. In that Team Challenge 2, each team would watch at least three different television news or talk shows for at least one half-hour per show as their frame of reference. The nature of the assignment and assessment would remain unchanged. But the analytical focus would adapt to shifting cognitive objectives. Figure 4 describes the format the Team Challenge would use in the second half of the course.

As before, the class was given the choice whether or not to conduct the Team Challenge. As before, they readily opted to do so. To ensure any negative team dynamics that may have arisen in earlier Team Challenges did not spill over into the second half of the course, students were also given the option to form new teams. Reflecting the synergy that had developed, they chose to retain the teams they had been working with.

Had it been a good idea to refocus the Team Challenge at midterm? Would students regress to minimal preparation of coursework when chapters and cases was no longer the team's focal point? Had the Team Challenge lost its novelty, and become an additional responsibility and chore rather than a means to deeper and more meaningful learning?

Once again, the outcomes were those hoped for. Not only did students maintain their prior level of preparation of required course and case reading, but also their Team Challenge performance spiked with the new focus. This was an especially constructive result given the subject matter, since oral presentation tends to be so intimidating to so many that it is often presented in the very last chapters of business communication textbooks ${ }^{8}$. While performing Team Challenge 2, students collectively and repeatedly observed professionals using the techniques 
they themselves were being taught. They became accustomed to analyzing presentation effectiveness, and with relevant criteria for assessing performance. In doing so, they saw some highly respected people making mistakes and recovering.

Collectively, the Team Challenges used throughout the Business Communication course delivered two additional positive but unintended consequences. By the time the course formally turned to assigned reading on oral presentation and long-form presentations to be delivered and graded individually, students had been doing and learning about oral presentation experientially for many weeks. Consequently, the class was able to approach the oral presentation module at a far more advanced level than had been possible in prior years, and students delivered the individual long-form oral presentations that complete the course at an unusually high level of competence and confidence. Moreover, there was a similar positive spillover when the module on teamwork was approached. Because the groundwork had been laid from the start of the course, and students had shared first-hand experience with teamwork for many weeks, the class was able to approach formal readings on teamwork at a far more sophisticated level.

Figure 2: Handout on Group Work

\section{TIPS FOR WORKING IN GROUPS}

Being able to work productively and well in groups is an important skill to learn today. This involves your individual participation and contribution, teamwork, leadership, communication, and interpersonal abilities. Learning to work comfortably and successfully in groups will help you in this and future courses, and in business. Today's workplace highly values these skills. Tips for effectively group and teamwork include:

- Participate fully. And do so as a member, not just a leader.

- Pick a leader. This should be someone with good organizational and interpersonal skills, who handles responsibility fairly, and who is reliable. The person selected should be someone the group trusts and feels comfortable with. The leader must possess strong interpersonal and collaborative skills, be able to foster an open and ethical communication climate characterized by trust/support/cooperation, be committed to the success of the group and each of its members, and be able to motivate high performance from all team members.

- The leader should ask group members what they feel most equipped and interested in contributing. It is important to get input from each individual about his/her role. Team members should not be told what they are going to do. They should be asked what they can and want to do. The leader should then coordinate the results, and look for things that need to be done that no one has requested.

- Collectively establish guidelines for group work, i.e. its values, ethics, rewards, and sanctions. Anticipate the worst and build in protections, put your "code" in writing, and stick to it.

- Collectively establish a work plan before any work is done. Define the end product and due date, break it up into tasks with the time each will take, and distribute assignments to specific group members with agreed upon deadlines clarified. Put it in writing for all, and stick to it. Build in "checkpoints" along the way. Revise your plan if, at a checkpoint, you find progress is off track.

- Divide the labor wisely, fairly, and equally. Your final product should be better than if you had done it alone because you are collaborating and have collective input. Each person ideally will do what s/he does best and enjoys most, and each person should contribute as much as every other person in the group.

- Recognize that we all have different strengths, interests, and styles. Learn to know what yours are, feel comfortable discussing them, recognize the strengths and interests of others, and adapt yours to facilitate theirs.

- Identify problems early on and solve them mutually. Respect the rights and opinions of all group members, recognize your responsibility as a participant, tackle any difficulties on the basis of the problem (not the person) and its consequences for the group, and have concrete realistic solutions to suggest.

- Apply communication skills. Remember to be you-oriented and reach common understanding with teammates. 
Figure 3: Peer Assessment Form for Teamwork

TEAM PROJECT: PEER ASSESSMENT

NAME:

GROUP:

COURSE/SEMESTER:

NAME OF GROUP LEADER

In the table below, write the name of all team members (including yourself). Then rank each member objectively, accurately, and fairly on each of the four criteria using a whole-number scale of 1 (low) to 4 (high). It is unlikely that every member of your team has performed at the same level.

\begin{tabular}{|l|l|l|l|l|l|}
\hline Name & Interest & Responsibility & Contribution & Teamwork & Overall \\
\hline & & & & & \\
\hline & & & & & \\
\hline & & & & & \\
\hline & & & & & \\
\hline \\
\hline
\end{tabular}

In the table below, write the name of all team members (including yourself). Then describe the type of contribution made by each group member (specific work they did) objectively, accurately, and fairly.

\begin{tabular}{|l|l|}
\hline Name___ & $\begin{array}{l}\text { Contribution/Work } \\
\text { Performed__ }\end{array}$ \\
\hline & \\
\hline & \\
\hline & \\
\hline & \\
\hline & \\
\hline
\end{tabular}

About how many hours did your group spend working together (meeting) on this project?

About how many hours did you spend working on this project (separate from meetings)?

On a scale of 1 (low) to 4 (high), rate the effectiveness of your group's performance as a team:

What have you learned about your strengths and weaknesses in maximizing the effectiveness of teamwork, as a result of this assignment?

Provide any comments you want to share with the professor about your team's performance on this assignment: 
Figure 4: Business Communication Team Challenge 2 - Second Half of Semester

\section{TEAM CHALLENGE, PART 2}

In this second half of the semester, your team challenge will focus on understanding and building proficiency in oral communication through a readily accessible and valuable vehicle: observing and learning from media professionals. Your team will select $\underline{3}$ or more TV news or talk shows to watch for at least $\underline{1} \underline{2}$ hour per show, identify $\underline{1}$ presenter as the strongest communicator and $\underline{1}$ presenter as the weakest, and explain your evaluations using your learning in this course. Assignment specifications and assessment methods will be the same as those used in previous Team Challenges. Follow this format:

- Identify the $\underline{3}$ programs watched, the date/time/station/format viewed, and the main topic discussed.

- List $\underline{3}$ terms from your textbook regarding oral presentation illustrated in what you viewed, and specify the illustrative example from your viewing for each term.

- Identify the 1 most effective communicator you viewed, using learning in this course to support your choice.

- Identify the 1 least effective communication you viewed, using learning in this course to support your choice.

- Give 1 critical thinking question regarding oral presentation stimulated by your viewing

- Answer that question, supporting it using 2 examples from course material or current examples found in valid media sources.

- Explain $\underline{2}$ presentation techniques you would use if you were a host or guest on any $\underline{1}$ of the shows you viewed.

Team Challenge-based learning was raising the level of dialog and learning in the classroom. Would that learning carry over into formal assessment vehicles synthesizing material covered over several weeks? The final exam essay question presented in Figure 5 was designed to determine this.

Figure 5: Business Communication Final Exam Essay Question on Team Challenge

\section{ESSAY QUESTION}

You have been assigned to a team that has performed weekly "team challenges" for this class. The learning goals for this ongoing assignment are two-fold: 1) to increase your competence when working in teams, and 2) to increase your understanding of the communication issues focal to each team challenge. Reflect upon your progress toward these goals, using $\underline{2}$ of the team challenges you have performed in this part of the course. For each: briefly summarize the scenario your team was assigned to, present and support 1 of your team's recommendations referring to course material as "proof," and explain the most important lesson learned from the class discussion that followed. Then, describe the $\underline{2}$ most important things you have learned about effective teamwork, using an example from your team's experience and supporting course material as "proof." Include an introduction. Provide a thoughtful and specific conclusion regarding your learning through the "team challenges," and pose a relevant critical thinking question (you need not answer it). Your learning from the textbook must be clear. Use this format:

\section{Introduction}

\section{Teamwork Assessment}

- $\quad$ Team Challenge 1 (identify/summarize, recommendation/supported, lesson learned).

- Team Challenge 2 (identify/summarize, recommendations/supported, lesson learned)

- $\quad$ Effective Teamwork 1 (lesson learned, team example, course material proof)

- $\quad$ Effective Teamwork 2 (lesson learned, team example, course material proof)

Conclusion (include critical thinking question)

Performance on the essay evidenced that the Team Challenge produced cognitive learning as well as the applied learning already seen, that the learning migrated from the team collective in which it occurred to the individual student, and that the learning was sustained over time. Conceived as a vehicle with the most basic of objectives, to ensure student completion of required readings and cases before class and to foster peer dialog, it delivered far more. Class was transformed through genuine and enthusiastic student engagement, in a vehicle designed 
for students but continued due to their choice and performance. As a result, the Team Challenges has not only become a Business Communication staple, but has been adapted to achieve learning objectives of courses as wide-ranging as the 100- level Perspectives of Business and Society course ${ }^{9}$ for textbook reading and casework, the 300-level Principles of Contemporary Arts Management course ${ }^{10}$ for analysis of overarching real-world cases such as The New York Times and The Apprentice: Martha Stewart, the 300-level Organizational Theory and Behavior course for learning linked to The Apprentice television series ${ }^{11}$, and the 400 -level Gender and Work Senior Seminar ${ }^{12}$ for analysis of Harvard Business Review cases and current stories in the media. In every instance, cognitive outcomes were positive, communication and teamwork skills were furthered, and spillover to positive classroom learning environs occurred.

\section{INITIATIVE 2: THE MANAGEMENT CONSULTANT SIMULATION}

Unlike the Team Challenge, the Management Consultant Simulation was an initiative conceived from necessity. The start of our College's intensive winter session coincided with the dates of an academic conference at which the instructor's work was to be presented. In order to be sure student learning would not be shortchanged, a foundational assignment needed to be designed that students could complete in the instructor's absence, in a relatively short time, and before they had done any other coursework.

The course was a 300-level Organizational Theory and Behavior class. It provides principles, applications, and tools basic to effective management of organizational behavior today. The areas it covers, and skills it builds, are consistently cited as central to contemporary workplace success and satisfaction. Topics include change, coaching, communication, conflict, decision- making, delegation/empowerment, diversity, feedback, globalization, goal setting, interviewing, leadership, motivation, organizational culture, perception, performance assessment, office politics, stress, and teamwork. Mirroring the focus of contemporary organizations, the course seeks to develop an understanding, appreciation, and capacity for achieving the ultimate goal of sustained high performance for organizations and their employees in today's ever-evolving, multicultural, competitive, transparent, and international environment in which workers are increasingly educated and expectant, and external stakeholders are increasing alert. To accomplish its objectives, individual, group, and organizational dynamics and processes are addressed through active learning. Essential interpersonal skills are inventoried and developed. Real world scenarios are simulated and analyzed ${ }^{13}$.

The underpinning of the course, then, is to develop ability and commitment to contribute to sustained high performance individually, collectively, and systemically. The Management Consultant Simulation was designed to immerse students first-hand, before any other course learning, in that foundational concept of high performance ${ }^{14}$. The assignment described below was distributed to students by email in advance of the course, with an introductory note presenting the assignment as having been created to provide a hands-on foundational exercise to launch their learning in the class, and that it was to be performed in lieu of the first three scheduled class meetings.

Resistant student feedback to the email was anticipated. None came. Figure 6 describes the assignment.

Returning from the conference after the first three scheduled days of the College's intensive winter session, this instructor approached the first meeting of the course with some trepidation. Most of the students were first-time students for the instructor; there was little history to draw upon in establishing the positive learning environment that seems especially pivotal in mini-sessions. The expectation was that students would say they had been asked to do too much in too short a period, had lost three days of class, had inadequate background to perform the exercise, and had not completed the assignment. Instead all students were present, memo reports were complete and substantive, beginning interest in the course was higher than it had ever been, and understanding of central concepts was in place at the start. Would that interest and learning be lost as the course progressed? Was there a way to come back to initial perspectives derived from the introductory consultant simulation as an integrative learning tool? What if students were given the opportunity to reflect upon their initial findings at mid-term, and again at end-term? 
Figure 6: Organizational Theory and Behavior Management Consultant Simulation

\section{MANAGEMENT CONSULTANT SIMULATION}

The Simulation: This assignment is designed to provide you with a contemporary framework for this course as you begin it. Simulating the role of a management consultant, you will select 1 company most interesting to you from those listed below. You will explore that company from the perspective of one "hired" by senior management to assess the company's performance, and to recommend how higher performance can be achieved. You are encouraged to select a company you know little about but are interested in.

Specifications: In assessing the company, you will want to apply the frames of reference provided in Chapters $\underline{1}$ and $\underline{2}$ of your textbook; you will find "high performance" described, and its requisite characteristics identified. As you are just starting the course, your findings are expected to be preliminary only. Bring those findings to our first regular class meeting in a $\underline{3+-p a g e}$ written/typed memo (with sources cited, and bibliography with full publication information - website address is not sufficient citation). Findings will be discussed in groups containing students who chose similar companies to explore, and then shared with the class as a whole. Your work on this assignment will be reflected in your participation grade for the course.

Select one of the following organizations to investigate: Air America Radio, Barnes and Noble, Bally's Fitness, Children's Television Workshop, CNN, Dell, Delta, Department of Homeland Security, E-Bay, Fox, Gap, General Electric, General Motors, Halliburton, Harley Davidson, Harpo, IBM, Jet Blue, Loreal, Lincoln Center, Martha Stewart Living, McDonalds, Merck, Metropolitan Transit Authority, Microsoft, Motorola, Museum of Natural History, NY Mets, NY Times, Nintendo, Nordstrom, NYPD, Reebok, Sony, Starbucks, Target, Tommy Hilfinger, Toyota, Toys-R-Us, The Trump Organization, United Postal Service, Verizon, Wal-mart, or Walt Disney Company.

\section{Follow this format for the memo report:}

Introduction (include identification and brief description of the company)

Performance Criteria ( $\underline{5}$ criteria from Chapter $\underline{2})$

1. (Criteria 1: definition)

2. (Criteria 2: definition)

3. (Criteria 3: definition)

4. (Criteria 4: definition)

5. (Criteria 5: definition)

Company Performance (discussion/example for each of the $\underline{5}$ performance criteria described above)

1. (Criteria 1: company's performance on that criteria)

2. (Criteria 2: company's performance on that criteria)

3. (Criteria 3: company's performance on that criteria)

4. (Criteria 4: company's performance on that criteria)

5. (Criteria 5: company's performance on that criteria)

Aspects of Company's Performance to be Explored Further

1.

2.

3.

Conclusion (include your rating of the company as a high performer using a whole number scale of $1 /$ low to $4 /$ high, the most important thing you learned about the company's performance, the most surprising thing you learned about the company's performance, and the most important lesson learned about achieving high performance)

The format for the midterm and final exams provided a ready vehicle for finding this out. Both exams are $90+$ minutes, and contain both objective and subjective sections. The latter contains at least three comprehensive essays; students may choose which one they want to answer, and are given one hour to write the essay. The mid-term and final exam included one essay that allowed students to revisit the management consultant assignment they had performed to begin the course, and extend the learning from that exercise through application of their subsequent course learning. A representative question designed for this purpose at midterm appears in Figure 7. 
Figure 7: Organizational Theory and Behavior Sample Essay Question on Management Consultant Simulation

\section{MIDTERM ESSAY QUESTION}

You began this course with an assignment simulating a management consultant exploring a contemporary company to recommend how higher performance can be achieved. Since performing that assignment, you have learned in depth what high performance is and what it depends on. Applying that knowledge, discuss whether or not the company has achieved each of the $\underline{5}$ characteristics of a high performance organization (HPO), identify $\underline{3}$ other core competencies we have learned about in this part of the course that are present or absent at the company, provide $\underline{1}$ specific company example for each competence, and recommend $\underline{2}$ company actions to achieve higher performance. Support your recommendations referring to text/case examples from this part of the course. Identify the company in the introduction. Conclude thoughtfully explaining the most important lesson learned from this analysis, and raising 1 relevant critical thinking question. Use this format:

Introduction (include identification of the company)

Analysis

- $\quad$ Presence of HPO characteristics (1-5)

- $\quad$ Presence or absence of other core competencies (3; and 1 example for each)

- $\quad$ Recommended actions/supported (2)

Conclusion (include most important lesson learned, and $\underline{1}$ critical thinking question)

Though it was not the easiest of the choices offered, the majority of students chose the Management Consultant Simulation essay to write. They were able to recall and apply the relevant factual background from the research they had conducted weeks earlier, and to analyze and suggest at a more advanced level.

But was this experience an anomaly, and was its positive outcome unique to the short-term nature of winter session? To find out, Management Consultant Simulation was replicated in the traditional-length spring semester that followed. This time, there was not an out-of-town commitment requiring advance distribution of the assignment by email. Instead, the assignment was presented face-to-face at the regularly scheduled first class, and students wre given a week to complete the simulation. As students could now select the companies they wanted to investigate before the simulation was conducted, students with similar interests but diverse demographic and psychographic attributes could be assigned to management consulting teams. Despite the larger size of the class and the challenges that work in assigned teams at the start of a semester might have posed, results were as positive as they had been in the winter session at all stages: initial simulation, mid-term, and end-term. The Management Consultant Simulation is now an integral feature of the course; it continues to be a vehicle for positive outcomes derived from reality-based learning.

Was the Management Consultant Simulation a particular fit with the Organizational Theory and Behavior course, or would it resonate equally well in other courses? To determine this, a 300-level course that posed real challenges to teach was sought. It was found in Principles of Contemporary Arts Management, an interdisciplinary course designed to introduce contemporary arts students to management, to introduce business students interested in contemporary arts management to those industries, and to introduce all students to the increasing convergence of business and contemporary arts. The course provides knowledge and techniques important to managers in the arts, entertainment, media, and related promotional industries ${ }^{15}$.

Principles of Contemporary Arts Management is a cross-listed course that fulfills requirements for both Communication and Management majors. From this stems the course's inherent strength (the opportunity to draw upon cross-functional perspectives similar to those students will encounter as practitioners), and its attendant difficulty (the need to provide pathways to those complexities in ways equally accessible and relevant to students with disparate majors). Where one student might gravitate toward a small, non-profit theater company, another student might relate instead to a large, commercial record company. What's more, neither student might want the class to know his/her true interests, making it all the more difficult for an instructor to select examples and cases meaningful to students. Additionally, the nature of the work its practitioners do involves an intricate dynamic. They must balance creative, editorial, economic, and environmental forces ${ }^{16}$ - be both left and right brain, function in both artistic and business 
arena. The ability to understand, appreciate, and navigate that complex interaction is the underpinning of the course, as ability to leverage high performance is the underpinning of the Organizational Theory and Behavior course. Might the Management Consultant Simulation be equally effective in heightening interest and understanding of complex core concepts in Principles of Contemporary Arts Management?

To find out, a Management Consultant Simulation was again created that targeted the foundational learning objectives of the course. Students were again provided choice in selecting the organization s/he would examine, and the assignment was again distributed at the start of the semester. Having learned the value of revisiting at midterm the insights students had gained from this assignment at the start of the course, the Management Consultant Simulation was offered as an activity to be done throughout the first half of the semester, to be reported on in a take-home section of the midterm exam. The assignment was described in the course syllabus, and appears in Figure 8.

\section{Figure 8: Principles of Contemporary Arts Management Course Management Consultant Simulation}

\begin{tabular}{|c|}
\hline MIDTERM EXAM MEMO REPORT - MANAGEMENT CONSULTANT FIELD TRIP \\
\hline $\begin{array}{l}\text { The tri-state area is a real world laboratory for contemporary arts management students and practitioners. To provide you the } \\
\text { opportunity to learn experientially, you will visit any contemporary arts facility of your choice during the first half of the course } \\
\text { and analyze it from the perspective of a management consultant applying your learning in the course. Keep the } 4 \text { interacting } \\
\text { creative, editorial, economic, and environmental forces in mind as you observe and analyze, and the various core competencies } \\
\text { you have learned in this course. You may visit the facility with a classmate, but your memo report ( } 3 \text { pages) must be your own } \\
\text { work/words. It is due at the start of your midterm exam. Use this format: }\end{array}$ \\
\hline Introduction (include identification of facility visited, date/time of visit, and reason for selecting it) \\
\hline $\begin{array}{l}\text { Summary (from a contemporary arts management perspective, provide your } \underline{3} \text { most important observations) } \\
1 . \\
2 . \\
3 .\end{array}$ \\
\hline $\begin{array}{l}\text { Analysis (from a contemporary arts management perspective, describe } \underline{2} \text { strengths and } \underline{2} \text { weaknesses observed) } \\
\text { 1. Strength } \\
\text { 2. Strength } \\
\text { 3. Weakness } \\
\text { 4. Weakness }\end{array}$ \\
\hline $\begin{array}{l}\text { Recommendations (from a contemporary arts management perspective, suggest } \underline{3} \text { actions/improvements the facility's managers } \\
\text { should take; support each suggestion with an example from the course) } \\
\text { 1. } \\
\text { 2. } \\
3 \text {. }\end{array}$ \\
\hline
\end{tabular}

Once again, it was anticipated that students would say the assignment was too demanding, open-ended, or dependant on student initiative. Instead, students reached out early in the semester to help brainstorm facilities they might visit that would best fit their interests and goals. The results were seen in the range of venues they collectively became familiar with. Through primary sourcing, the students had developed a management perspective linking sophisticated academic concepts to complex practical application in such entities as a top-ranked cable news station, the Metropolitan Museum of Art, an off-Broadway theater company, a local historical society, a college performing arts center, a celebrity fundraising event for the American Cancer Society, a cutting edge Cineplex entertainment center, Yankee Stadium, Lincoln Center, an on-line magazine, a touring jazz ensemble, and a major dance company. The observations chronicled and conclusions derived far surpassed those previously produced by traditional secondary case analysis. They became the basis for subsequent in-class discussion sharing findings, as had occurred in the Organizational Theory and Behavior course. The Management Consultant Simulation appears to be a learning tool 
adaptable to various courses. It is now a regular feature of the Principles of Contemporary Arts Management, too, and has been adapted to the Perspectives of Business and Society ${ }^{17}$ to help explore corporate social responsibility.

\section{INITIATIVE 3: THE BOOKSTORE ADVENTURE}

The Bookstore Adventure was conceived as a result of a discussion that occurred in the 300-level Business Communication course when the module on conducting research was taught. The various steps and techniques the research process entails were presented: identifying the right questions, finding and accessing information through primary and secondary sources, evaluating and finalizing sources, processing the information that has been found, and analyzing and interpreting the data ${ }^{18}$. The response was revealing: something between glazed looks and pending meltdown appeared on student faces. Ironically, several colleagues had commented earlier that same day about their frustration at increasingly finding student research papers with bibliographies containing internet addresses as the only source descriptors. The stress the topic was producing in students seemed oddly reminiscent of the dismay faculty colleagues were expressing. The technological divide was palpable in the mutual bafflement about methods and expectations that seem to be natural to each but foreign to the other.

The challenge could not be ducked. For learning to occur, there had to be a way to overcome the divide, to find common ground, to identify a concrete place comfortable and positive for students through which to teach them. Trying to see the stressors of the research process through their eyes, it seemed useful to try to replace the differing frames of reference through common experience - to remember, as an instructor, what it was like to be a college student conducting research.

Intuitively, story telling appeared to be the vehicle. Rather than berating the students' skill deficits, discussion centered on how interesting it is to see changes in the research process. Pre-digital modes of research were described: going to the card catalog and looking up the Dewey Decimal number for a topic being researched, walking through the stacks of books and periodicals to locate the topical collection, pulling out and looking through each and every source that seemed relevant, discovering things in doing so that would not have been found otherwise, manually writing and referencing highlights on individual index cards which would become the basis of 50+ page hand-typed papers - each page of which needed to be retyped to make any changes. Instead of today's search engines, abstracts, electronic links, keywords, and information overload, the formative research tools that preceded them included card catalogs, library stacks, paper, pens, fingers, stamina, curiosity, and imagination.

As that research experience was described, the juxtaposition became clear: an essentially manual research process having been upended by modern technology. Where effective research had depended on the ability to know the finite place to start one's investigation and how to expand through collections one stumbled upon, research today depends on the inverse ability to narrow down a seemingly endless array of available possibilities.

These reflections were greeted by silence. After a minute or two, a student raised his hand and said, "If I had to write a research paper that way, I wouldn't be able to do it. I wouldn't know where to start." Unknowingly, that student provided the bridge to create a common reality through which learning might occur. Students would be provided with a way to regain the experience of being physically immersed with a written collection, as a means to becoming more fully engaged in the research process. But how could that be done?

It seemed that the optimal experience would be in a place familiar and attractive to students, and would be offered as an optional assignment. The students were asked if they would like to have that real world learning experience and extra credit opportunity. Glazed looks were replaced by smiles; students leaned forward asking for details and specifications. Figure 9 shows the initiative created as a result.

It was expected that five of the twenty-five students would choose to take the Bookstore Adventure. But virtually every student did so. Their memo reports were the next surprise. In addition to evidencing fulfillment of the learning objective regarding the research process, the writing had more substance, originality, and voice. Moreover, students revealed aspects of their interests, habits, and natures that were invaluable when later selecting teaching 
examples that would resonate with them. Importantly, many students began future research by searching through the stacks of the College Library before conducting the online searches that had been their prior start point.

\section{Figure 9: Business Communication Bookstore Adventure}

\section{THE BOOKSTORE ADVENTURE}

The Assignment: This is an optional, extra credit opportunity designed for those interested in broadening their research competence by conducting manual information searches which may stimulate creativity, critical thinking, and research questions as unexpected sources are encountered.

Specifications: Spend a few hours in the bookstore of your choice. A minimum of $\underline{2}$ hours must be spent exploring the aisles of the bookstore (you may enjoy spending some time in the music, video, or coffee sections, but do not include that in the assignment). Walk through the bookstore and identify $\underline{5}$ sections you would not otherwise browse. Identify $\underline{2}$ book titles in each section you are surprised to find, and that you are glad you did. For our next class, prepare a $\underline{3+-}$ page memo report that presents your findings. End with a thoughtful conclusion that includes the most important lesson learned from this assignment, and a critical thinking question stimulated by the experience. Use this format:

\section{Introduction}

\section{Bookstore Investigation}

1. Subject 1

- $\quad$ Book 1: (What you were surprised/glad to find, its brief summary, and why you chose/value it)

- $\quad$ Book 2: (Use the same format as used for Book 1)

2. Subject 2 (Use the same format as used for Subject 1)

3. Subject 3 (Use the same format as used for Subject 1)

4. Subject 4 (Use the same format as used for Subject 1)

5. Subject 5 (Use the same format as used for Subject 1)

Conclusion/Critical Thinking Question

Where the results unique to this class and its students? To determine whether outcomes would be replicated, the Bookstore Adventure option was offered again in the 300-level Organizational Theory and Behavior class when research methods were covered. Student response and results were similar to those of students in the Business Communication class. Figure 10 provides representative excerpts from the memo reports students have submitted to complete this assignment. The Bookstore Adventure has become a staple of my courses covering research methods. 
Figure 10: Representative Excerpts from Bookstore Adventure Memo Report

\section{STUDENT 1: VISITED COMPUTER, CAREER, ENTREPRENEUR, COOK BOOK, AND TRANSPORTATION}

- Introduction: The Bookstore investigation was an assignment to demonstrate that physical places like bookstores and libraries still have a substantial amount of information and knowledge compared to the Internet. Most students have become comfortable with finding information on the Internet and have forgotten the skills to do research in a physical place like a library, or don't know how to find a certain section in a bookstore or library. Sure, the Internet is fast and easy, but not all the information may be correct or valid. At the library or bookstore you can gain a social learning experience rather than being isolated in a room looking at a screen.

- Conclusion: My trip to the bookstore was a great adventure. I felt researching there physically to be more enjoyable than sitting down at home looking up information online. I was glad to find books I was interested in, and even more surprised to find new sections that could be helpful to me in learning, development, self-improvement, and entertainment. I even bought a book for my own knowledge that had nothing to do with my classes; but it was for my own self-interest, and it was on sale.

STUDENT 2: VISITED SPORTS, TRAVEL NARRATIVE, PERSONAL FINANCE, REFERENCE, AND PEOPLE/POLITICS

- Introduction: Leaving my home, I wondered what bookstore I would go to. I stopped at the first one I came upon. For some reason, I skipped breakfast and started looking immediately (I might have been excited). I started with the first section I saw, the sports section (most people would be surprised at this)...

- Conclusion: When I left the bookstore, I checked the time. To my surprise I had broken the time minimum ... by over an hour (three hours plus total)! On this trip to commonly unexplored vicinities, I have found and learned a lot. Compared to the Internet, in some ways, this is a lot less of a hassle. With the Internet, you are given something depending on what keyword you input. With bookstores, one can obtain a wealth of knowledge with less time used (surfing the Internet for useful data could take days).

\section{STUDENT 3: VISITED EXOTIC PETS, PARENTING, HUMOR, RELIGION, AND MUSIC REFERENCE}

- Conclusion: This exercise was the best. It took me back to the old days where computers weren't that popular, and you took your time doing research in the library. I also stumbled on a lot of interesting books. At first I thought this assignment was too long, but when I got into it time flew by fast. I had to pull myself out of the store. I was about to spend close to $\$ 50$ bucks on good reading material.

STUDENT 4 (MBA STUDENT): VISITED HEALTH/MEDICINE, THINGS LOCAL, COMPUTERS/TECHNOLOGY, HISTORY, AND SOCIAL SCIENCE

- Introduction: For this assignment I went to one of my favorite bookstores. I spent about two hours happily roaming around in sections I would not normally visit (I usually end up in the children's section with my kids).

- Social Sciences Section: Binge - What Your College Student Won't Tell You is a current look into the every day life of college students. My co-worker believes she knows what goes on in the life of her freshman daughter. If I give this book to her she may change her mind (providing that she reads it!). I also could learn a lot from it. I never thought to look to a book to help me understand the differences between what I went through as an undergraduate in the 1980's and what the undergraduates in my classes are going through now.

- Conclusion: Can exploring bookstore sections help you view other people and your surroundings differently? The most important lesson I learned is to look beyond the obvious. The old saying, 'You can't judge a book by its cover,' applies to everything around you. I visited places I would not normally even think to go into; in every one I found a book I would love to read or give. I have changed my mind on how to view things. I now know I must be more open and adventurous. I must look past the cover of everything to see what is really there. 


\section{ADAPTATION}

The three initiatives described above have a common thread. All were designed to further characteristics of effective pedagogy identified by the American Association of Higher Education's Seven Principles in Action, and by AACSB standards ${ }^{19}$. All were designed to enhance student engagement in their learning. And all were built on a common foundation. Instructors interested in adapting the Team Challenge, Management Consultant Simulation, or Bookstore Adventure may find it useful to consider the following ten core tenets relied upon in the creation of those initiatives:

1. Link the initiative to course objectives. Target specific and relevant outcomes for the assignment, so it is a distinct tool for learning rather than a diversion. Clarify those objectives to students.

2. Formalize the modality. Incorporate the initiative into the syllabus or other materials where other course assignments and deadlines are posted. The initiative should be seen as part of the course, and its place in the course should be clear.

3. Make the assignment and specifications explicit. Describe what is to be done, how it will be assessed, and what discretion students have. Include background establishing the learning value of the initiative.

4. Offer meaningful incentives and an equal chance to receive them. Motivate optimal participation through positive rewards for learning achieved, and negative sanctions for not fulfilling commitments. Design rewards and sanctions that create a level playing field for all students. This may include infusing a participation grade into the course, and including performance on the initiatives as a way to build the grade.

5. Include peer assessment of team assignments. Inoculate against social loafing, promote strong contribution, and develop capacity for objective self-assessment by establishing clear and relevant criteria for teamwork, conveying them to all at the start of the assignment, and using appropriate mechanisms for applying them to measure individual and collective performance of the team's members.

6. Prepare for the team meltdown. Have a back-up plan in place if a team becomes so dysfunctional that its performance is impaired. Determine in advance if, for example, a team may fire a member; if members of a team can expect a decision about a team problem if all members are not present when the problem is brought to you; or whether the team will be empowered to solve its problems or you will intervene upon request. Specify the negative impact on one's course grade if $s /$ he does not fulfill assigned responsibilities to the team, and the positive impact on one's course grade if s/he steps up to lead a disintegrating team to positive synergy.

7. Give requisite support. Identify the competencies integral to performing the assignment, and train students in those skill sets. At a minimum, show students how to create a project work plan that specifies every task to be completed, who is responsible for each task, and completion date for each task. Consider incorporating submission of the project work plan to the instructor as part of completing the assignment.

8. Keep the initiative relevant and fresh. Modify the assignment as needed to reflect changing course content, and to reflect the interests and needs of students in the course.

9. Tell your colleagues what you are doing. Anticipate that students will tell other students and instructors about the initiatives and may request that other courses incorporate active learning, reality-based assignments. Informing your colleagues about the initiatives you are using, the role of the initiatives in fostering learning in your courses, and validating the teaching methods that they use may help your colleagues respond in ways that support both your learning methods and theirs.

10. Do your part. Put at least as much effort into the initiative as you expect the students to, build learning from the initiative into the classroom, apply the criteria and assessment measures that were established, provide 
prompt and concrete feedback, deliver the rewards and sanctions that were offered, assess whether the initiative was effective - and be ready to adapt or abandon it if it was not.

\section{CONCLUSION}

Designing, implementing, and evaluating initiatives such as the three presented in this paper is not simple, and is an ongoing process. If the effectiveness of an initiative wears off, instructors must retool or let go of it. Alternatively, if an initiative is highly effective, instructors may want to see whether effectiveness can be replicated in other classes.

Throughout the continual cycle of creation, assessment, and reconfiguration, all ten of the core tenets described above have been useful. But the last of those ten points, "do your part," may deserve special attention. Students offered active learning exercises for the first time, especially by an instructor new to them, may perceive that the instructor is shirking his/her responsibility to teach, and is delegating it to the students. Students may mistake carefully constructed solid learning opportunities for fun and games. It is possible that students may misconstrue a pedagogical initiative as experimentation at their cost, or even as professional arrogance.

None of those problematic scenarios have been the experience of this author, however. Collectively, the ten guidelines have provided a paradigm in which engaged learning experiences are seen as the deliberate, strategic pathways to deep and meaningful learning that is their intent. Each activity is seen as one of several means to an end as a path to successfully accomplish the course objectives. No one activity receives undo attention, is the focal point of the course, or is an end in itself. The instructor who designs, mounts, and assesses such pedagogy within this paradigm will likely have a solid footing. S/he should know from the start, however, that this is labor intensive; it is unlikely to be the easy route.

On the other hand, instructors who teach best when student engagement is strong, when the learning journey is taken with their students, when the classroom and real world are bridged, when the classroom is infused with grounded excitement, and when the material literally comes to life for students might well want to take this road. It need not mean abandoning traditional teaching methods. But opting to include active, reality-based learning tools allows for the infusion of ever-fresh pedagogy created to stimulate, leverage, and support the learning moments that appear.

To "do your part" also means knowing one's limits as well as one's strengths, and choosing to use pedagogy consistent with those strengths. Those who find the above guidelines outside their core competencies or interests may be most effective using more traditional techniques. Those for whom the guidelines resonate, though, may find them to be a starting place in adapting the Team Challenge, Management Consultant Simulation, or Bookstore Adventure for use in their classes, or in creating initiatives of their own to achieve the benefits that such engaged learning experiences can contribute.

\section{ENDNOTES}

${ }^{1}$ Generation Y (also called Echo Boomers, Millenials, Internet Generation, or Nexters) generally refers to the 76 million Americans born after 1980. For descriptors of the four generations cohabiting the contemporary workplace, see Eisner, S., Managing Generation Y, Advanced Management Journal, 2006 (forthcoming at time of press).

${ }^{2}$ Eisner, S. A Model for Win-Win Interviewing: The 5 C's, Management in Practice, No. 1, 2005; Teaching Workplace Skills Through Integrative Exercises, Journal of College Teaching and Learning, Vol. 1, Number 11, November 2004, pp. 61-72; Teaching Generation Y College Students: Three Initiatives, Journal of College Teaching and Learning, Vol. 1, Number 9, September 2004, pp. 69-84, The Class Talk Show, Advanced Management Journal, Vol. 69, Number 1, Winter 2004, pp. 34-42 and 49; and Effective Pedagogy for Business Schools Post-9/11/01, Journal of Business and Economic Research, Vol. 1, Number 1, January 2003, pp. 59-75. 
${ }^{3}$ AACSB International - The Association to Advance Collegiate Schools of Business, Proposed Eligibility Procedures and Standards for Business Accreditation, March 10, 2003.

${ }^{4}$ Page, D. and Mukherjee, A. Improving Undergraduate Student Involvement in Management Science and Business Writing Courses Using the Seven Principles in Action, Education, Vol. 120, Number 3, 2000, p. 547 (12).

${ }^{5}$ U. S. News \& World Report. America's Best Colleges, 2005 and 2006.

${ }^{6}$ Eisner, S. Syllabus: Business Communication, BMGT 307. Ramapo College of New Jersey. 2005.

${ }^{7}$ See endnote \#2 (ibid).

${ }^{8}$ The required textbook in the course was Bovee, C., Thill, J. and Schatzman B., Business Communication Today, 7th Ed., Prentice Hall, 2003; the final two chapters covered oral presentation.

${ }^{9}$ Perspectives of Business and Society is a General Education course and the first required course for business majors at Ramapo College. Students are introduced to contemporary business within its changing social and governmental context. Current events are infused in exploring the actions and environments of business, expectations of and accountability to primary and secondary stakeholders, and origins of economic systems and related public policies. Key issues facing business and society are explored. Topics include affirmative action, changing social contract, civic engagement, community relations, consumerism, diversity, downsizing, ecology, education, employer-employee relations, ethics, globalization, media/communication, social responsibility, technology, transparency, and work/family (Eisner, S. Syllabus: Perspectives of Business and Society, BBAD 115, Ramapo College of New Jersey, 2005).

${ }^{10}$ Principles of Contemporary Arts Management is an interdisciplinary, cross-listed 300-level course that fulfills requirements for both Communications and Management majors. The course introduces contemporary arts students to management, business students to contemporary arts industries, and all students to the increasing convergence of business and contemporary arts. It provides knowledge and techniques important to mangers in the arts, entertainment, media, and related promotional industries (Eisner, S. Syllabus: Principles of Contemporary Arts Management, BMGT/CCOM 302, Ramapo College of New Jersey, 2005).

${ }^{11}$ Organizational Theory and Behavior is a required Business School course and is described elsewhere in this paper. For details of applying the Team Challenge for learning linked to The Apprentice, see Eisner, "Apprentice Watch: Learning Through Reality TV,” Proceedings, 2006 College Teaching and Learning Conference.

12 The Gender and Work Senior Seminar helps students understand the implications for the lives of men and women of fundamental demographic shifts in which women are projected to be the majority of U.S. workers soon, and builds relevant workplace competencies. Topics include Workplace 2000, demographics and trends, gender equity, gender and style/communication/leadership/management, gender equity, stumbling blocks and strategies for overcoming them, work-life balance, and career tracks and career management (Eisner, S. Syllabus: Gender and Work Senior Seminar, ZSRS 428, 2005).

${ }^{13}$ Eisner, S. Syllabus: Organizational Theory and Behavior, BMGT 327, Ramapo College of New Jersey, 2005.

${ }^{14}$ The course textbook (Schermerhorn, J., Hunt, J., and Osborn, R. Organizational Behavior, $9^{\text {th }}$ edition, John Wiley \& Sons, 2005) describes five characteristics of high-performance organizations: 1) value, respect, and empower human talent; 2) mobilize team synergy, initiative, and self-direction; 3) infuse information and production technologies throughout operations, and integrate those technologies in a way that optimizes the work of people; 4) promote ongoing and shared learning, growth, and development; and 5) focus on delivering the best and maximizing customer satisfaction through total quality management. 
${ }^{15}$ Eisner, S. Syllabus: Principles of Contemporary Arts Management, BMGT/CCOM 302, Ramapo College of New Jersey, 2005.

${ }^{16}$ Eisner, S. Contemporary Arts Management: A $21^{\text {st }}$ Century Model, Proceedings, Society for Advancement of Management International Management Conference, 2001.

${ }^{17}$ See endnote \#9 (ibid).

${ }^{18}$ Bovee, C., Thill, J, and Schatzman, B. Business Communication Today, Chapter 10, 7th Ed.; Prentice Hall, 2003.

${ }^{19}$ See endnotes \#3 (ibid) and 4 (ibid).

\section{NOTES}




\section{NOTES}

